\title{
Study on the Efficiency of Grape Seed Meals Used as Antioxidants in Layer Diets Enriched with Polyunsaturated Fatty Acids Compared with Vitamin E

\section{-Author(s)}

\section{Olteanu $\mathrm{M}^{\prime}$ \\ Criste RD' \\ Panaite TD' \\ Bunduc $\mathrm{V}^{11, \mathrm{II}}$ \\ Panaite $C V^{I V, V}$ \\ Ropota $\mathrm{M}^{\prime}$ \\ Mitoi $\mathrm{M}^{\mathrm{vI}}$}

National Research Development Institute for Animal Biology and Nutrition, Calea Bucuresti, no 1, Balotesti, 077015, Ilfov, Romania;

" University of Agricultural Sciences and Veterinary Medicine, lasi, Romania;

III SC Avicola Lumina SA, Soseaua Tulcei, no. 111, Comuna Lumina, 907175, Constanta;

Iv University of Agricultural Sciences and Veterinary Medicine, Boulevard Marasesti, no 59, 011464, Bucuresti, Romania;

SC BIOMIN ROMANIA SRL

VI Institute of Biology Bucharest, 296, Splaiul Independentei, 060031, Romania.

\section{ABSTRACT}

The 4-week study was conducted with 180 Lohmann Brown layers (52 weeks of age). The layers were assigned to three groups (C, E1 and E2). The basal diet (group C) consisted mainly of corn, soybean meal and corn gluten, and contained $19 \%$ crude protein and $11.58 \mathrm{MJ} / \mathrm{kg}$ metabolizable energy. The diets for groups E1 and E2 differed from group $C$ by the inclusion of $5 \%$ flax meal and of dietary antioxidants. The concentration of $\alpha$-linolenic acid in the fat of E1 and E2 diets was almost 10 times higher than in group C. E1 diet was supplemented with vitamin E (100 mg/kg feed, DM), while E2 diet was supplemented with $2 \%$ grape seed meal (polyphenols: $630.890 \mu \mathrm{g}$ gallic acid equivalents/g sample; flavonoids: $5.065 \mu \mathrm{g}$ rutin equivalents/g sample; antioxidant capacity: $28.468 \mathrm{mM}$ trolox equivalents/g sample). The antioxidant capacity of E2 was higher than in C, but lower than in E1. Haugh units of the eggs (18 eggs/group) harvested during the last experimental week were not significantly different among groups. The $\omega-6 / \omega-3$ polyunsaturated fatty acids (PUFAs) ratio in the fat from the eggs was $4.46 \pm 0.11(E 1)$ and $4.52 \pm 0.21(E 2)$, three times lower $(p<0.05)$ than the control group $(14.70 \pm 0.43)$. In group E1 in particular, but also in group E2, the concentration of total polyphenols in the egg yolk was higher $(p<0.05)$ than in group $C$.

\section{INTRODUCTION}

Corresponding author e-mail address Criste Rodica Diana

National Research Development Institute for Animal Biology and Nutrition, Balotesti,

Ilfov, Romania.

Zip code: 077015

Tel: $\quad(+040) 0213512082$

Email: cristerodica@yahoo.com

\section{-Keywords}

Eggs; PUFAs; antioxidants; grape seed meal; quality.
Submitted: January/2016 Approved: March/2016
Literature studies have shown that the structure and matureness of the feeds given to animals directly influence the feeding value of the resulting animal foods, with beneficial effects on human health (Simopoulos, 2008; McManus and Hunt, 2013; Flachs et al., 2014). The inclusion of ingredients rich in polyunsaturated fatty acids (PUFAs) in layer diets may enrich the eggs with $\omega-3$ fatty acids (Criste et al., 2009). Such eggs among the few foods that can meet the human dietary requirements of $\omega-3$ fatty acids (Simopoulos, 2008). However, the unsaturated fatty acids present in animal feeds provide an adequate environment for the development of rancidity because they are very sensitive to oxidation reactions during storage, when nutrients may react with the free oxygen to form free radicals. Rancidity deteriorates the feeding value of feeds, leading to economic losses due to its adverse effects on animal performance and health. Oxidized dietary fat increases the exposure to free radicals, inducing oxidative stress in the animal organism (Miret et al., 2003), and the exposure of the animal foods to lipid oxidation makes them less acceptable by consumers (Sparks, 2006).

Synthetic antioxidants produced from phenolic structures, such as the butylated hydroxyanisole (BHT), or tertiary butyl hydroxyl quinone (TBHQ), and the presence of natural antioxidants in the feed, such as 
Olteanu M, Criste RD, Panaite TD, Bunduc V, Panaite CV, Ropota M, Mitoi M
Study on the Efficiency of Grape Seed Meals Used as Antioxidants in Layer Diets Enriched with Polyunsaturated Fatty Acids Compared with Vitamin E vitamin E, carotenoids and plant extracts, may prevent the adverse effects of rancidity (Fellenberg and Speisky, 2006). Winery by-products are rich in polyphenols (Katalinić et al., 2010) and flavonoids (Yilmaz and Toledo, 2004), which are antioxidants, and have shown to have beneficial effects on layer performance and egg quality (Su et al., 2008; Hu et al., 2013). Such products inhibit lipid peroxidation of diets rich in $\omega-3$ PUFAs and ensure good oxidative status of the eggs, which is beneficial for the human health. In this context, our study aimed at comparing the antioxidant efficiency of grape seed meal included in layer diets enriched in PUFAs with vitamin E, and the effects on live performance and on egg quality.

\section{MATERIAL AND METHOD}

The experiment was conducted for four weeks. In total, 180, 52-week-old Lohmann Brown layers were randomly distributed into three groups (C, E1 and E2), with 60 layers each. The layers were assigned to groups to obtain similar average weight among groups: $1667.00 \mathrm{~kg} \pm 42.40(\mathrm{C}) ; 1665.20 \mathrm{~kg} \pm 33.46$ (E1), and $1673.00 \mathrm{~kg} \pm 32.44$ (E2). The layers were housed (two layers/cage) in Zucami three-tier digestibility cages (60 cm width $\times 60 \mathrm{~cm}$ length $\times 40 \mathrm{~cm}$ height), which allowed daily recording feed intake, excreta output, and egg production.

Diets were formulated according to the results of the chemical analysis of the feed ingredients, and supplied the layers' nutritional requirements (NRC, 1994). The mathematical model proposed by Burlacu et al. (1999) was used to calculate the formulas.

Birds were managed according to the Lohmann Brown-Classic Layer Management Guide. A lighting regime of 16 hours per day was applied, also according to Lohmann Brown-Classic Layer Management Guide. The environmental temperature maintained at 22$24^{\circ} \mathrm{C}$, and air relative humidity at $60-70 \%$ throughout the experimental period. Birds had free access to feed and water.

Table 1 shows the composition of the experimental diets. The basal diet (group C) consisted mainly of corn, soybean meal, and corn gluten, and contained 19\% crude protein and $11.58 \mathrm{MJ}$ metabolizable energy/ $\mathrm{kg}$. The E1 and E2 group diets differed from group $\mathrm{C}$ by the inclusion of $5 \%$ flax meal and of dietary antioxidants (Table 1): diet E1 was supplemented with $100 \mathrm{mg}$ vitamin E/kg feed on dry matter (DM) basis, while group E2 was supplemented with $2 \%$ grape seed meal.
Table 1 - Feedstuff composition of the experimental diets (\%)

\begin{tabular}{lccc}
\hline Specification & C & E1 & E2 \\
\hline Corn & 60.35 & 55.35 & 55.35 \\
Flax meal & - & 5 & 5 \\
Grape seed meal & - & - & 2 \\
Soybean meal & 25 & 25 & 23 \\
Gluten & 1 & 1 & 1 \\
Oil & 2 & 2 & 2 \\
Monocalcium phosphate & 1.25 & 1.25 & 1.25 \\
Calcium carbonate & 8.9 & 8.9 & 8.9 \\
Salt & 0.3 & 0.3 & 0.3 \\
Methionine & 0.15 & 0.15 & 0.15 \\
Choline & 0.05 & 0.05 & 0.05 \\
Vitamin-mineral premix (VMP)* & 1 & & 1 \\
VMP* + 75 ppm vit E & & 1 & \\
\hline TOTAL & 100 & 100 & 100 \\
\hline
\end{tabular}

${ }^{*}$ Content per kg diet: vitamin $A: 13,500$ IU; vitamin $D_{3}: 3,000$ IU; vitamin E: 27 mg; vitamin $\mathrm{K}_{3}: 2 \mathrm{mg}$; vitamin $\mathrm{B}_{1}: 2 \mathrm{mg}$; vitamin $\mathrm{B}_{2}: 4.8 \mathrm{mg}$; pantothenic acid: $14.85 \mathrm{mg}$; nicotinic acid: $27 \mathrm{mg}$; vitamin $B_{6}: 3 \mathrm{mg}$; vitamin $B_{7}: 0.04 \mathrm{mg}$; vitamin $B_{0}: 1 \mathrm{mg}$; vitamin $B_{12}: 0.018 \mathrm{mg}$; vitamin C: $25 \mathrm{mg}$; manganese: $71.9 \mathrm{mg}$; iron: $60 \mathrm{mg}$; copper: $6 \mathrm{mg}$; zinc: $60 \mathrm{mg}$; cobalt: $0.5 \mathrm{mg}$; iodine: $1.14 \mathrm{mg}$; selenium: $0.18 \mathrm{mg}$.

The following performance parameters were monitored during the entire experimental period: average daily feed intake ( $\mathrm{g} /$ day/layer), feed conversion ratio ( $\mathrm{g}$ feed/g egg mass), laying percentage (\%), and average egg weight ( $\mathrm{g} /$ day). Eggs were harvested (18 eggs/group) at the beginning and in the end of the experiment. The external and internal egg quality parameters albumen weight (g), yolk weight (g), eggshell weight $(\mathrm{g})$, eggshell thickness $(\mathrm{mm})$, eggshell breaking strength (kf), yolk color intensity, and Haugh units were measured. After these measurements, six yolk samples were pooled (3 eggs/sample)/group for the determination of yolk fatty acid profile, total polyphenol content, flavonoid content, and antioxidant capacity in methanolic yolk extracts.

Standard methods were used to determine the concentration of the main nutrients from the feedstuffs and experimental diets: dry matter (DM) was determined by the gravimetric method, according to SR ISO 6496:2001; crude protein (CP) was determined by the Kjeldahl method, according to SR EN ISO 5983-2:2009; ether extract (EE) was determined by extraction in organic solvents, according to SR ISO 6492:2001; fatty acid profile was determined by gas chromatography according to SR CEN ISO/TS 177642:2008; crude fiber (CF) was determined by successive hydrolysis in alkali and acid environment, according to SR EN ISO 6865:2002; ash (Ash) was determined by the gravimetric method, according to SR EN ISO 2171:2010; gross energy and the metabolisable energy were determined by calculation with regression equations for layers; Kreiss reaction was determined 
Olteanu M, Criste RD, Panaite TD, Bunduc V, Panaite CV, Ropota M, Mitoi M
Study on the Efficiency of Grape Seed Meals Used as Antioxidants in Layer Diets Enriched with Polyunsaturated Fatty Acids Compared with Vitamin E in accordance to STAS 12266-84; peroxide index and fat acidity were determined using volumetric methods, according to STAS 12266-84;

Egg white weight, yolk weight, eggshell weight, yolk color intensity and Haugh unit were determined using the Egg Analyzer TM, type 05-UM-001, manufactured by Orka Technology Ltd; eggshell thickness with an eggshell thickness gauge device, manufactured by Orka Technology Ltd, respectively, and eggshell breaking strength with an egg force reader device, manufactured by Orka Technology Ltd.

The content of total phenols in the methanolic extracts of the diets, egg white, and yolk was determined according to the method described by Mihailovic et al. (2013), and results are expressed as $\mu \mathrm{g}$ gallic acid equivalents/g sample ( $\mu \mathrm{g} \mathrm{GAE} / \mathrm{g}$ ). The flavonoid content of the methanolic feed extracts was determined according to the method described by Zhishen et al. (1999), and the results are expressed as $\mu \mathrm{g}$ rutin equivalents/g sample ( $\mu \mathrm{g} R \mathrm{RE} / \mathrm{g}$ ). The antioxidant capacity of the methanolic feed and yolk extracts was determined by the DPPH method proposed by Marxen et al. (2007), results were expressed as mM trolox equivalents/g sample (mM TE/g).

The effects of treatments were tested by analysis of variance using the GLM procedure of the Minitab software (version 17, Minitab ${ }^{\circledR}$ Statistical Software), with treatment as fixed effect, according to the model $Y_{i}=T_{i}+e_{i}$, where $Y_{i}$ was the dependent variable, $T_{i}$ is the treatment and $e_{i}$ is the error. When overall F-test was significant, differences between means were declared significant at $p<0.05$ using the test of Tukey.

\section{RESULTS AND DISCUSSIONS}

Flax meal contained $44.50 \mathrm{~g}$ of $\omega-3$ PUFAs $/ 100 \mathrm{~g}$ fat and $22.43 \mathrm{~g}$ of $\omega-6$ PUFAs $/ 100 \mathrm{~g}$ fat, which gives $0.504 \omega-6 / \omega-3$ ratio. This ratio was determined as 11.71 in wheat, 31.88 in corn, and 11.68 in soybean meal. The flax meal chemical composition obtained is in agreement with that reported by Criste et al. (2009).

Grape seed meal contained $10.64 \%$ protein, $1.56 \%$ fat, $630.89 \mu \mathrm{g}$ GAE/g polyphenols, $5.065 \mu \mathrm{g}$ RE/g flavonoids, and presented an antioxidant capacity of $28.468 \mathrm{mM}$ TE/g.

The chemical analyses of the experimental diets (Table 2) showed that all contained equal protein (about 19\% protein) and energy (about $15 \mathrm{MJ} / \mathrm{kg}$ gross energy and $11 \mathrm{MJ} / \mathrm{kg}$ metabolizable energy) values.

Due to the presence of flax meal, the fat of the experimental feeds presented different fatty acids profiles (Table 3 ). According to the analyses, $\alpha$-linolenic acid level, a $\omega-3$ PUFA, was almost 10 times higher in E1 and E2 diets than in diet $C(8.78 \mathrm{~g} / 100 \mathrm{~g}$ fat in diet E1 and $10.62 \mathrm{~g} / 100 \mathrm{~g}$ fat in group E2 compared with 0.95 $\mathrm{g} / 100 \mathrm{~g}$ fat in group $\mathrm{C}$ ). On the other hand, linoleic acid, a $\omega-6$ PUFA, was slightly higher in diet C (52.83 $\mathrm{g} / 100 \mathrm{~g}$ fat) than in diets E1 and E2, which contained $44.19 \mathrm{~g} / 100 \mathrm{~g}$ fat and $47.18 \mathrm{~g} / 100 \mathrm{~g}$ fat, respectively. These results explain why the dietary $\omega-6 / \omega-3$ PUFA ratio was 7.54 times lower in diet E1 and 8.77 times lower in diet E2 compared with diet C (Table 3). The differences between the two experimental groups (E1 and E2) in terms of $\alpha$-linolenic acid content and $\omega-6 / \omega-3$ PUFA ratio are due to the fact that the grape seed meal contained $\omega-3$ fatty acids (Table 3 ).

The determination of the parameters for the antioxidant capacity of the feeds showed that both polyphenol and flavonoid concentrations in the E2 diet (grape seed meal) were higher than in diet $C$, but lower compared with diet E1, which contained with vitamin $\mathrm{E}$ (Figures 1 and 2). The antioxidant capacity ranged between 1.260 and $1.427 \mathrm{mM} \mathrm{TE} / \mathrm{g}$, with the highest value recorded for in diet E2 (Figure 3).

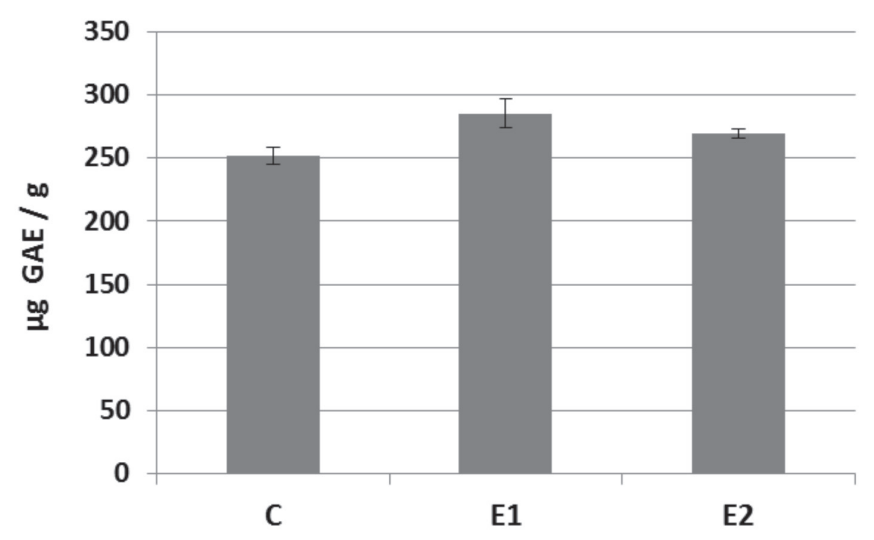

Figure 1 - Concentration of total polyphenols in methanolic feed extracts, expressed as $\mu \mathrm{g}$ gallic acid equivalents/g sample ( $\mu \mathrm{g} \mathrm{GAE} / \mathrm{g}$ ) (C: control group; E1: experimental group 1; E2: experimental group 2)

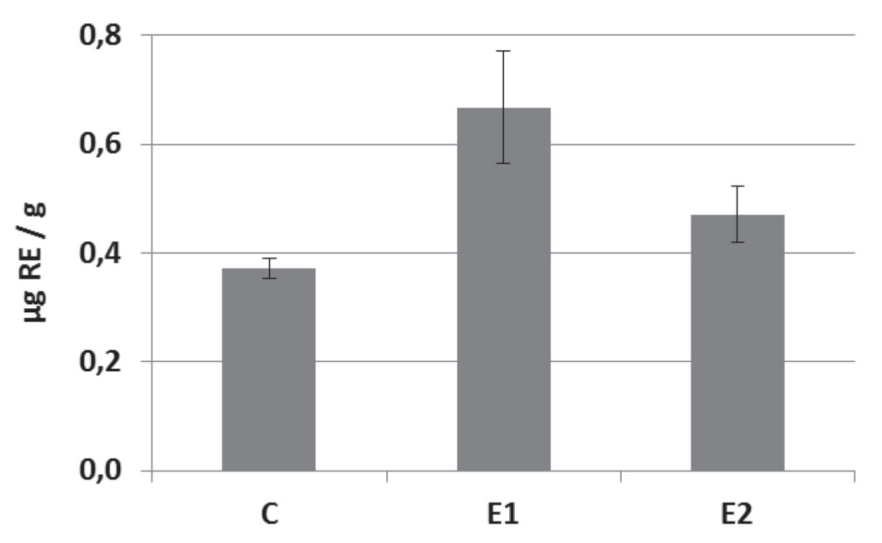

Figure $\mathbf{2}$ - Concentration of total flavonoids in methanolic feed extracts, expressed as $\mu \mathrm{g}$ rutin/g sample ( $\mu \mathrm{g} \mathrm{RE} / \mathrm{g}$ ) (C: control group; E1: experimental group 1; E2: experimental group 2) 
Table 2 - Analyzed nutrient (\%) and energy (MJ/kg) composition of the experimental diets ${ }^{\star}$

\begin{tabular}{lcccccccccc}
\hline Specification & DM & OM & CP & EE & CF & NFE & Ash & GE & ME \\
\hline C & 89.56 & 70.29 & 19.11 & 4.02 & 4.72 & 45.06 & 11.98 & 14.99 & 11.58 \\
E1 & 90.01 & 70.54 & 19.75 & 4.46 & 4.41 & 44.55 & 12.37 & 15.16 & 11.25 \\
E2 & 89.90 & 76.88 & 19.07 & 4.57 & 5.11 & 43.20 & 13.02 & 14.96 & 11.17 \\
\hline
\end{tabular}

"Where: DM: dry matter; OM: organic matter; CP: crude protein; EE: ether extract; CF: crude fiber; NFE: nitrogen-free extract; GE: gross energy; ME: metabolizable energy

Table 3 - Fatty acid profiles of the experimental diets and their ratio ( $\mathrm{g} / 100 \mathrm{~g}$ fat)

\begin{tabular}{|c|c|c|c|c|}
\hline Fatty acids & & $C$ & E1 & E2 \\
\hline Myristic acid & C 14:0 & 0.11 & 0.16 & 0.14 \\
\hline Pentadecanoic acid & C 15:0 & 0.26 & 0.23 & 0.24 \\
\hline Pentadecenoic acid & C $15: 1$ & 0.09 & 0.28 & 0.18 \\
\hline Palmitic acid & C 16:0 & 8.97 & 10.79 & 10.02 \\
\hline Palmitoleic acid & C $16: 1$ & 0.19 & 0.15 & 0.14 \\
\hline Stearic acid & C 18:0 & 2.82 & 3.29 & 3.20 \\
\hline Oleic acid & C $18: 1 n 9$ & 30.88 & 30.18 & 26.82 \\
\hline Linoleic acid & C $18: 2 n 6$ & 52.83 & 44.19 & 47.18 \\
\hline Linolenic acid $\alpha$ & C $18: 3 n 3$ & 0.95 & 8.78 & 10.62 \\
\hline Heneicosanoic acid & C 21:0 & 0.37 & 0.27 & 0.23 \\
\hline Eicosadienoic acid & C $20: 2 n 6$ & 0.09 & 0.27 & 0.20 \\
\hline Eicosatrienoic acid & C $20: 3 n 6$ & 0.16 & 0.19 & 0.00 \\
\hline Docosadienoic acid & C $22: 2 n 6$ & 0.47 & 0.45 & 0.30 \\
\hline Docosatrienoic acid & C $22: 3 n 6$ & 0.14 & 0.13 & 0.18 \\
\hline Eicosapentaenoic acid & C $20: 5 n 3$ & 0.47 & 0.45 & 0.49 \\
\hline Other fatty acids & & 0.30 & 0.19 & 0.06 \\
\hline$\omega-3$ & & 1.42 & 9.03 & 11.11 \\
\hline$\omega-6$ & & 54.16 & 45.68 & 48.35 \\
\hline$\omega-6 / \omega-3$ & & 38.14 & 5.06 & 4.35 \\
\hline
\end{tabular}

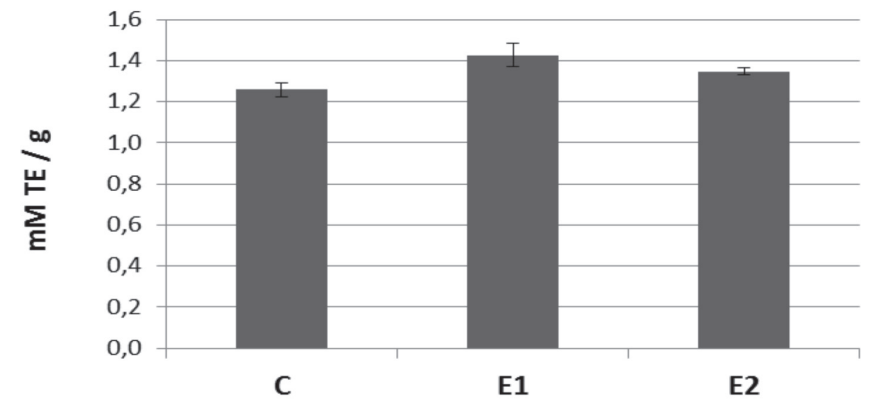

Figure 3 - Antioxidant capacity in methanolic feed extracts, expressed as mM trolox equivalents/g sample (mM TE/g) (C: control group; E1: experimental group 1; E2: experimental group 2)

There was a strong correlation between antioxidant capacity and polyphenol concentration, given by equation: $Y=0.0652 x-15.336, R^{2}$ coefficient $=$ 0.9725 , and between antioxidant capacity and flavonoid concentration, given by equation: $Y=$ $5.9453 x-0.8146, R^{2}$ coefficient $=0.9948$.

The effect of the antioxidants included in the feeds of the two experimental groups (E1 and E2), compared with the control group, was calculated by the determination of the fat degradation index in feed samples collected 14 and 28 days after feeds were manufactured. The peroxide index and fat acidity results show that both vitamin E (group E1) and grape seed meal (group E2) preserved the feeding quality of these feeds, despite having a high concentration of PUFAs. However, the results of the Kreiss reaction, although it is only a qualitative method, showed that diets E1 and E2 presented some degree of rancidity due to the fatty acid profile of their fat (Table 4).

Table 4 - Evolution of the dietary fat degradability indices

\begin{tabular}{lcccc}
\hline Specification & $\begin{array}{c}\text { Period } \\
\text { (day) }\end{array}$ & C & E1 & E2 \\
\hline Peroxide index & 14 & 2.96 & 3.16 & 5.80 \\
(ml thiosulfate $0.1 \mathrm{~N} / \mathrm{g}$ fat) & 28 & 3.61 & 4.19 & 6.35 \\
\hline Fat acidity & 14 & 19.37 & 8.80 & 18.67 \\
(mg KOH/g fat) & 28 & 29.32 & 32.20 & 22.30 \\
\hline Kreiss reaction & 14 & negative & negative & negative \\
\hline
\end{tabular}

Relative to performance parameters, group $C$ layers presented significantly $(p<0.05)$ lower average daily feed intake than those in groups E1 and E2, and therefore, group $C$ feed conversion ratio was also significantly $(p<0.05)$ better compared with E1 and E2 layers (Table 5). These findings are in agreement with literature studies, which reported layer performance improvement and egg cholesterol reduction with the dietary inclusion 
Table 5 - Performance parameters (average values/group)*

\begin{tabular}{|c|c|c|c|c|c|}
\hline Specification & C & E 1 & E 2 & SEM & P \\
\hline Average daily feed intake (g CF/layer/day) & $\begin{array}{c}106.804^{c} \\
\pm 0.823\end{array}$ & $115.567^{\mathrm{a}} \pm 0.958$ & $\begin{array}{c}110.857^{b} \\
\pm 0.770\end{array}$ & 0.854 & $<0.0001$ \\
\hline Feed conversion ratio (kg CF/kg egg) & $\begin{array}{r}1.693^{b} \\
\pm 0.139\end{array}$ & $\begin{array}{l}1.776^{a} \\
\pm 0.150\end{array}$ & $\begin{array}{l}1.779^{a} \\
\pm 0.144\end{array}$ & 0.0139 & $<0.0001$ \\
\hline Laying percentage (\%) & $\begin{array}{l}89.613^{a} \\
\pm 1.286\end{array}$ & $\begin{array}{l}91.005^{a} \\
\pm 1.134\end{array}$ & $\begin{array}{l}89.841^{\mathrm{a}} \\
\pm 1.009\end{array}$ & 1.149 & 0.656 \\
\hline Average egg weight (g/egg) & $\begin{array}{l}63.061^{b} \\
\pm 0.146 \\
\end{array}$ & $65.045^{\mathrm{a}} \pm 0.149$ & $62.314^{c} \pm 0.207$ & 0.170 & $<0.0001$ \\
\hline
\end{tabular}

"Where: SEM: standard error of the mean; means in the same row with no common superscript are significantly different $(p<0.05)$

Table 6 - External and internal egg quality parameters (average values/group)*

\begin{tabular}{|c|c|c|c|c|c|}
\hline Specification & $\mathrm{C}$ & E1 & E2 & SEM & $\mathrm{P}$ \\
\hline Egg white weight, g & $\begin{array}{l}37.63^{a} \\
\pm 0.81\end{array}$ & $\begin{array}{l}37.73^{\mathrm{a}} \\
\pm 0.59\end{array}$ & $\begin{array}{l}35.17^{\mathrm{a}} \\
\pm 0.91\end{array}$ & 0.784 & 0.040 \\
\hline Yolk weight, g & $\begin{array}{l}16.63^{a} \\
\pm 0.34\end{array}$ & $\begin{array}{l}17.39^{a} \\
\pm 0.32\end{array}$ & $\begin{array}{l}16.30^{a} \\
\pm 0.31\end{array}$ & 0.322 & 0.058 \\
\hline Eggshell weight, $g$ & $\begin{array}{l}8.24^{a} \\
\pm 0.15\end{array}$ & $\begin{array}{l}8.33^{a} \\
\pm 0.18\end{array}$ & $\begin{array}{l}8.35^{\mathrm{a}} \\
\pm 0.16\end{array}$ & 0.167 & 0.883 \\
\hline Eggshell thickness, mm & $\begin{array}{l}0.375^{a} \\
\pm 0.01\end{array}$ & $\begin{array}{l}0.371^{\mathrm{a}} \\
\pm 0.01\end{array}$ & $\begin{array}{l}0.360^{\mathrm{a}} \\
\pm 0.01\end{array}$ & 0.007 & 0.345 \\
\hline Eggshell breaking strength, $\mathrm{kf}$ & $\begin{array}{l}4.414^{a} \\
\pm 0.17\end{array}$ & $\begin{array}{l}4.124^{\mathrm{a}} \\
\pm 0.24\end{array}$ & $\begin{array}{l}4.316^{a} \\
\pm 0.30\end{array}$ & 0.243 & 0.695 \\
\hline Yolk color intensity & $\begin{array}{l}5.11^{\mathrm{a}} \\
\pm 0.17\end{array}$ & $\begin{array}{c}4.67^{a} \\
\pm 0.18\end{array}$ & $\begin{array}{c}3.89^{b} \\
\pm 0.14\end{array}$ & 0.167 & $<0.0001$ \\
\hline Haugh unit & $\begin{array}{l}68.7^{\mathrm{a}} \\
\pm 0.60\end{array}$ & $\begin{array}{l}69.30^{\mathrm{a}} \\
\pm 0.78\end{array}$ & $\begin{array}{l}69.40^{\mathrm{a}} \\
\pm 0.39\end{array}$ & 0.614 & 0.703 \\
\hline
\end{tabular}

"Where: SEM: standard error of the mean; means in the same row with no common superscript are significantly different $(p<0.05)$

Table 7 - Fatty acids profile of the yolk fat (average values/group)* ( $\mathrm{g} / 100 \mathrm{~g}$ fat)

\begin{tabular}{|c|c|c|c|c|c|c|c|c|}
\hline Fatty acids & \multicolumn{2}{|c|}{ C } & \multicolumn{2}{|c|}{ E 1} & \multirow{2}{*}{$\frac{\text { E 2 }}{0.30^{\mathrm{a}, \mathrm{b}}}$} & \multirow[b]{2}{*}{ \pm 0.010} & \multirow{2}{*}{$\begin{array}{c}\text { SEM } \\
0.009\end{array}$} & \multirow{2}{*}{$\frac{P}{0.003}$} \\
\hline Myristic acid & $0.32^{a}$ & \pm 0.011 & $0.27^{b}$ & \pm 0.008 & & & & \\
\hline Myristoleic acid & $0.08^{a}$ & \pm 0.005 & $0.05^{b}$ & \pm 0.006 & $0.06^{a, b}$ & \pm 0.007 & 0.006 & 0.008 \\
\hline Pentadecanoic acid & $0.06^{a}$ & \pm 0.002 & $0.06^{a}$ & \pm 0.007 & $0.05^{a}$ & \pm 0.010 & 0.007 & 0.573 \\
\hline Pentadecenoic acid & $0.14^{a}$ & \pm 0.009 & $0.16^{a}$ & \pm 0.020 & $0.11^{\mathrm{a}}$ & \pm 0.020 & 0.017 & 0.124 \\
\hline Palmitic acid & $25.09^{a}$ & \pm 0.167 & $23.67^{b}$ & \pm 0.300 & $23.93^{b}$ & \pm 0.315 & 0.268 & 0.004 \\
\hline Palmitoleic acid & $3.18^{a}$ & \pm 0.156 & $2.94^{a}$ & \pm 0.127 & $3.17^{a}$ & \pm 0.121 & 0.136 & 0.416 \\
\hline Heptadecanoic acid & $0.13^{a}$ & \pm 0.003 & $0.13^{a}$ & \pm 0.013 & $0.11^{\mathrm{a}}$ & \pm 0.013 & 0.011 & 0.409 \\
\hline Heptadecenoic acid & $0.14^{a}$ & \pm 0.013 & $0.13^{a}$ & \pm 0.014 & $0.11^{\mathrm{a}}$ & \pm 0.024 & 0.018 & 0.383 \\
\hline Stearic acid & $10.45^{a}$ & \pm 0.347 & $11.52^{\mathrm{a}}$ & \pm 0.348 & $10.53^{\mathrm{a}}$ & \pm 0.613 & 0.454 & 0.212 \\
\hline Oleic acid & $33.85^{a}$ & \pm 0.554 & $33.18^{a}$ & \pm 0.651 & $33.66^{a}$ & \pm 0.699 & 0.638 & 0.752 \\
\hline Linoleic acid cis & $18.16^{a}$ & \pm 0.488 & $18.10^{\mathrm{a}}$ & \pm 0.184 & $18.80^{\mathrm{a}}$ & \pm 0.195 & 0.321 & 0.261 \\
\hline Linolenic acid $\gamma$ & $0.13^{a}$ & \pm 0.002 & $0.10^{\mathrm{b}}$ & \pm 0.006 & $0.11^{a, b}$ & \pm 0.009 & 0.005 & 0.035 \\
\hline Linolenic acid $\alpha$ & $0.32^{c}$ & \pm 0.014 & $1.57^{b}$ & \pm 0.023 & $1.79^{a}$ & \pm 0.070 & 0.043 & $<0.0001$ \\
\hline Eicosadienoic acid & $0.17^{\mathrm{a}}$ & \pm 0.004 & $0.08^{b}$ & \pm 0.027 & $0.09^{a, b}$ & \pm 0.029 & 0.023 & 0.031 \\
\hline Eicosatrienoic acid & $0.32^{\mathrm{a}}$ & \pm 0.020 & $0.25^{a, b}$ & \pm 0.022 & $0.23^{b}$ & \pm 0.018 & 0.019 & 0.014 \\
\hline Erucic acid & $0.16^{\mathrm{a}}$ & \pm 0.039 & $0.04^{b}$ & \pm 0.010 & $0.04^{b}$ & \pm 0.017 & 0.025 & 0.006 \\
\hline Eicosatrienoic acid & $0.27^{a}$ & \pm 0.017 & $0.24^{a}$ & \pm 0.016 & $0.21^{\mathrm{a}}$ & \pm 0.018 & 0.016 & 0.068 \\
\hline Arachidonic acid & $4.06^{a}$ & \pm 0.149 & $3.76^{a, b}$ & \pm 0.109 & $3.24^{b}$ & \pm 0.165 & 0.142 & 0.003 \\
\hline Nervonic acid & $0.31^{\mathrm{a}}$ & \pm 0.013 & $0.20^{\mathrm{b}}$ & \pm 0.010 & $0.17^{b}$ & \pm 0.012 & 0.012 & $<0.0001$ \\
\hline Docosatetraenoic acid & $1.54^{a}$ & \pm 0.062 & $0.27^{b}$ & \pm 0.019 & $0.24^{b}$ & \pm 0.027 & 0.040 & $<0.0001$ \\
\hline Docosapentaenoic acid & $0.11^{b}$ & \pm 0.008 & $0.19^{a}$ & \pm 0.011 & $0.24^{a}$ & \pm 0.023 & 0.015 & $<0.0001$ \\
\hline Docosahexaenoic acid & $0.96^{c}$ & \pm 0.049 & $2.27^{b}$ & \pm 0.083 & $2.79^{a}$ & \pm 0.118 & 0.087 & $<0.0001$ \\
\hline Other fatty acids & $0.06^{\mathrm{a}}$ & \pm 0.032 & $0.02^{a}$ & \pm 0.023 & $0.02^{\mathrm{a}}$ & \pm 0.020 & 0.025 & 0.547 \\
\hline$\omega-3$ & $1.66^{b}$ & \pm 0.065 & $5.05^{a}$ & \pm 0.089 & $5.03^{a}$ & \pm 0.095 & 0.084 & $<0.0001$ \\
\hline$\omega-6$ & $24.37^{a}$ & \pm 0.487 & $22.57^{b}$ & \pm 0.273 & $22.71^{b}$ & \pm 0.136 & 0.332 & 0.003 \\
\hline$\omega-6 / \omega-3$ & $14.70^{a}$ & \pm 0.584 & $4.46^{b}$ & \pm 0.043 & $4.52^{b}$ & \pm 0.085 & 0.342 & $<0.0001$ \\
\hline
\end{tabular}

"where: SEM: standard error of the mean; means in the same row with no common superscript are significantly different $(p<0.05)$ 
Olteanu M, Criste RD, Panaite TD, Bunduc V, Panaite CV, Ropota M, Mitoi M
Study on the Efficiency of Grape Seed Meals Used as Antioxidants in Layer Diets Enriched with Polyunsaturated Fatty Acids Compared with Vitamin E of winery by-products, such as grape seeds extracts ( $\mathrm{Hu}$ et al., 2013), and 6\% grape seed meal (Su et al., 2008). The highest laying percentage $(91.005 \%)$ was recorded in the group E1, but it was not statistically different from the other groups (Table 5).

External and internal egg quality parameters determined on eggs harvested at the end of the experiment were not significantly different $(p<0.05)$ among the three groups, except for yolk color intensity (Table 6). In the study of Kara et al. (2016), layers were fed a diet supplemented with $0 \%$ (control group), $4 \%$, or $6 \%$ grape pomace (experimental groups) for 12 weeks, but no significant effects on external or internal egg quality parameters were observed.

The yolk fatty acid profile was different among groups. The concentrations of both $\alpha$-linolenic and docosahexaenoic acids, which are $\omega-3$ PUFAs, were significantly $(p<0.05)$ higher in the yolk of the eggs collected from the experimental groups E1 and E2 compared with the control (Table 7). The concentration of docosapentaenoic acid was also significantly higher $(p<0.05)$ in the yolk of the eggs collected from the experimental groups (E1, E2) compared with the control group (C).

Although the concentration of $\alpha$-linolenic acid in E1 and E2 diets was about 10 times higher than in diet $C$, the concentration of this acid in the eggs was only 5-6 times higher in the experimental groups compared with group $C$. Differences in the yolk fatty acids profile between E1 and E2 were also determined. For instance, $\alpha$ linolenic acid concentration was significantly higher $(p<0.05)$ in group E2 compared with group E1 (Table 7), which was expected due to $\alpha$-linolenic acid differences between the two diets (Table 3). As expected, considering the fatty acid profile shown in Table 3, the $\omega-6 / \omega-3$ ratios in the egg yolks of the experimental groups were 4.46 (E1) and 4.52 (E2), which are three times lower than in group $C$ (Table 7 ). These results prove the production of eggs enriched in $\omega-3$ PUFAs.

Regarding the oxidative status, in group E1 in particular, but also in group E2, total polyphenol concentrations in methanolic yolk and albumen extracts were significantly higher than in the control group (Figure 4). Differently from the oxidative status results obtained in group E1 (treated with $100 \mathrm{mg}$ vitamin E/kg feed) in the present study, lqbal et al. (2014) concluded, in an experiment with broilers, that the dietary replacement of vitamin E by grape polyphenols (GPP) resulted in better antioxidant status when $50 \mathrm{mg} / \mathrm{kg}$ of GPP was added to the diet.

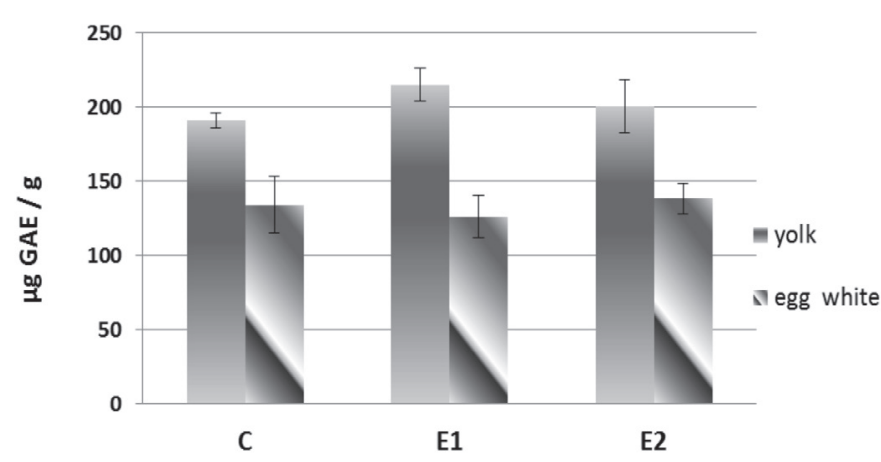

Figure 4 - Concentration of the total polyphenols in methanolic egg extracts, expressed as $\mu g$ gallic acid equivalents/g sample ( $\mu \mathrm{g} \mathrm{GAE} / \mathrm{g}$ ) (C: control group; E1: experimental group 1; E2: experimental group 2)

Antioxidant capacity, determined in methanolic yolk extract, ranged between 0.750-0.845 mM TE/g, with the highest value recorded in group E1 (Figure 5). In the study of Kara et al. (2016), cited above, egg yolk malondialdehyde levels were reduced with the dietary supplementation of $4 \%$ and $6 \%$ grape pomace, showing that grape pomace may potentially extend egg shelf life. Malondialdehyde is also a lipid peroxidation marker (Gaweł et al., 2004). In the present study, a strong correlation between the antioxidant capacity of the methanolic yolk and feed extracts was determined, according to the equation: $Y=0.9408 x+0.1621, R^{2}$ coefficient $=0.9974$.

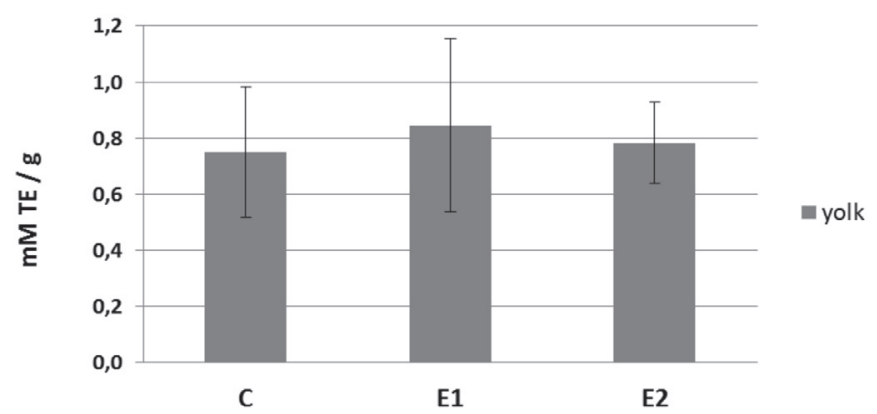

Figure $\mathbf{5}$ - Antioxidant capacity of methanolic yolk extracts, expressed as $\mathrm{mM}$ trolox equivalents/g sample (mM TE/g) (C: control group; E1: experimental group 1; E2: experimental group 2)

\section{CONCLUSIONS}

The concentration of polyphenols and flavonoids was higher in the diets with $5 \%$ flax meal, containing either $100 \mathrm{mg}$ vitamin E/kg feed (group E1) or $2 \%$ grape seed meal (group E2), compared with diet C, and a strong correlation between antioxidant capacity and the concentrations of polyphenols $\left(R^{2}=0.9725\right)$ and of flavonoids $\left(R^{2}=0.9948\right)$ in the E1 and E2 diets was determined. Both vitamin $\mathrm{E}$ and the grape seed meal preserved the feeding qualities of the compound feeds, despite containing high levels of PUFAs. 
Olteanu M, Criste RD, Panaite TD, Bunduc V, Panaite CV, Ropota M, Mitoi M

Considering the yolk fatty acid profile of the eggs laid by E1 and E2 layers, the $\omega-6 / \omega-3$ PUFA ratio was about three times lower compared with that of the control group. Total polyphenol contents of methanolic yolk extracts of groups E1 and E2 were higher than in group $C$. The determination of the antioxidant capacity in the methanolic yolk extracts proved that there is a strong correlation between polyphenol concentration and antioxidant capacity. A strong correlation between the antioxidant capacity of the methanolic yolk and feed extracts was also determined $\left(R^{2}=0.9974\right)$.

Although the concentration of PUFAs was higher in the diets with $5 \%$ flax meal containing either 100 mg vitamin E/kg feed (group E1) or 2\% grape seed meal (group E2) as antioxidants, compared with the control diet, the oxidative status was balanced both in the feeds and in the eggs due to the presence of grape seed meal, a natural additive derived from wine production, compared with vitamin $\mathrm{E}$.

\section{ACKNOWLEDGEMENTS}

This paper is part of the project PN-II-INEUK-2012-1-0027, through the program INNOVATION - Subprogram EUROPEAN COOPERATION EUREKAEUROSTARS - PN II, run with the financial support of MEN, CCCDI-UEFISCDI.

\section{REFERENCES}

Burlacu GH, Cavache A, Burlacu R, Surdu I. Ghid pentru alcatuirea ratiilor de hrana la pasari. Balotesi: IBNA; 1999

Criste RD, Panaite TD, Ciurescu C, Ropota M, Rachieru D. Effects of moderate $(5 \%)$ levels of linseed in layer diets. Archiva Zootechnica 2009;12(3):11-21.

Fellenberg MA, Speisky H. Antioxidants: their effects on broiler oxidative stress and its meat oxidative stability. World's Poultry Science Journal 2006;62(01):53-70.

Flachs P, Rossmeisl M, Kopecky J. The effect of n-3 fatty acids on glucose homeostasis and insulin sensitivity. Physiological Research 2014;63 Suppl 1:93-118.

Gaweł S, Wardas M, Niedworok E, Wardas P. Malondialdehyde (MDA) as a lipidperoxidation marker. Wiad Lek. 2004;57(9-10):453-455.
Study on the Efficiency of Grape Seed Meals

Used as Antioxidants in Layer Diets Enriched with Polyunsaturated Fatty Acids Compared with Vitamin E

Hu R, Wang Y, Wang X, Yang T, Chen S, Yang X, et al. Grape seed extract: effects on performance and yolk cholesterol content in laying hens. Chinese Journal of Animal Nutrition; 2013.

Iqbal Z, Ali R, Sultan JI, Ali A, Kamran Z, Khan SA, et al. Impact of replacing grape polyphenol with vitamin $\mathrm{E}$ on growth performance, relative organs weight and antioxidant status of broilers. The Journal of Animal \& Plant Sciences 2014;24(5):1579-1583.

Kara K, Kocaoğlu Güçlü B, Baytok E, Şentürk M. Effects of grape pomace supplementation to laying hen diet on performance, egg quality, egg lipid peroxidation and some biochemical parameters. Journal of Applied Animal Research 2016;44(1):303-310.

Katalinić V, Moțina SS, Skroza D, Generalit I, Abramović H, Miloš M, et al. Polyphenolic profile, antioxidant properties and antimicrobial activity of grape skin extracts of 14 Vitis vinifera varieties grown in Dalmatia (Croatia). Food Chemystry 2010;119:715-723.

Marxen K, Vanselow KH, Lippemeier S, Hintze R, Ruser A, Hansen UP. Determination of DPPH radical oxidation caused by methanolic extracts of some microalgal species by linear regression analysis of spectrophotometric measurements. Sensors 2007;7:2080-2095.

McManus A, Hunt W. Consumption of $\Omega-3$ fatty acids and women's health OA Women's Health 2013;1:11

Mihailović V, Matić S, Mišić D, Solujić S, Stanić S, Katanić J, et al. Chemical composition, antioxidant and antigenotoxic activities of different fractions of Gentiana asclepiadea L. roots extract. EXCLI Journal 2013;12:807-823.

Miret S, Sáiz MP, Mitjavilo MT. Effects of fish oil- and olive oil-rich diets on iron metabolism and oxidative stress in the rat. British Journal of Nutrition 2003;89:11-18

Simopoulos AP. The importance of the omega-6/omega-3 fatty acid ratio in cardiovascular disease and other chronic diseases. Experimental Biology and Medicine 2008;233(6):674-688.

Sparks NHC. The hen's egg-is its role in human nutrition changing?. World's Poultry Science Journal 2006;62:308-315.

Su X, Liu H, Yu W, Pang Z. Zhuang Y. Study of Effect of Grape Seed on Growth Performance in Pigs and Hens. China Animal Husbandry and Veterinary Medicine 2008;35(2):9-13.

Yilmaz Y, Toledo RT. Health aspect of functional grape seed constituents. Trends in Food Science and Technology 2004;15:422-433.

Zhishen J, Mengcheng T, Jianming W. The determination of flavonoid contents in mulberry and their scavenging effects on superoxide radicals. Food Chemistry 1999;64:555-559.

*** Lohmann Brown-Classic-Management Guide-LOHMANN TIERZUCHT $\mathrm{GMBH}$, Germania 
